\title{
Early Diagnosis and Management of Hepatic Artery Complications Following Living Donor Liver Transplantation
}

\author{
KAMAL MAMDOUH, M.D. and AHMED KHALIL, M.D. \\ The Department of General Surgery, Faculty of Medicine, Ain Shams University, Cairo, Egypt
}

\begin{abstract}
Background: Liver Transplantation (LT) has become the treatment of choice for patients with end-stage liver disease. However vascular problems are considered the most serious complications reported after LT. These complications can lead to increased morbidity, graft loss, and patient death. Hepatic Artery Thrombosis (HAT) represents a major cause of graft loss and mortality after liver transplantation.
\end{abstract}

Aim of Study: To assess hepatic artery complications after Living-Donor Liver Transplantation (LDLT) and to make an early diagnosis with different ways of management, with clinical follow-up.

\section{Design: Historical cohort study.}

Patients and Methods: Between March 2008 and February 2018, 323 adult to adult LDLT were performed at Ain Shams Organ Transplant Center (ASCOT) in Ain Shams Specialized Hospital. The overall male/female ratio was $280 / 43$. We retrospectively identified and analyzed hepatic artery complications in recipients.

Results: The overall incidence of hepatic artery complications was $4.3 \%(n=14)$ and early HA thrombosis $1.8 \%$ $(\mathrm{n}=6)$; all treated surgically, two patients were retransplanted, late HAT $1.2 \%(n=4)$; treated medically and HA stenosis $0.6 \%$ $(\mathrm{n}=2)$ treated with stenting by interventional radiology.

Conclusion: Prevention and proper treatment of hepatic artery complications is required to achieve better survival among patients undergoing LDLT.

Key Words: Hepatic artery thrombosis - Posttransplant complications.

\section{Introduction}

LIVING Donor Liver Transplantation (LDLT) is a modality that has been developed to overcome the shortage of available cadaveric livers for transplantation [1]

Correspondence to: Dr. Kamal Mamdouh El-Sayed, E-Mail: Kamal elsayed@med.asu.edu.eg kamalelsaid83@.gmail.com
Living donor liver transplantation has a high risk of vascular complications because of complex reconstruction of the hepatic artery and portal vein. Thus, a significant percentage of liver grafts are still lost from vascular complications posttransplant. Early and accurate diagnosis of vascular complications is crucial for increasing the survival rate of the graft. If untreated, many vascular complications may progress to severe hepatic failure or biliary sepsis, resulting in graft failure [2].

Arterial complications occurring post-transplant include thrombosis or hemodynamically significant hepatic artery stenosis; diffuse aneurysms; and arteriovenous fistulas. The thrombosis of the Hepatic Artery (HAT) is the most frequent one [3].

Bile ducts are exclusively dependent on the blood supply from the hepatic artery (HA). The HAT usually presents with biliary ischemic lesions such as necrosis with biliary leakage, ischemic stricture(s), cholangitis, and ultimately a multiorgan failure and graft dysfunction [4] .

Imaging techniques play a decisive role in the diagnosis of vascular complications. Although angiography is the traditional gold standard, it is an invasive procedure. Computed Tomography (CT) causes radiation effects and Magnetic Resonance Imaging (MRI) is more costly. Moreover, these techniques are not available at the bedside of severely ill patients in the Intensive Care Unit (ICU). As a non-invasive, cost-effective and nonradioactive modality with bedside availability, ultrasonography is a very useful imaging modality in the early post-operative period after liver transplantation. Spectral and color Doppler US can provide useful information for monitoring vascular complications [5]. 
Various therapeutic options for managing HAT, including arterial reconstruction, surgical thrombectomy, hepatic artery stenting and radiologically guided thrombolysis, are available. Retransplantation is restricted by both graft availability and the patient's general condition.

The objective of this study is to assess hepatic artery complications after Living-Donor Liver Transplantation (LDLT) and to make an early diagnosis with different ways of management, with clinical follow-up.

\section{Patients and Methods}

An Institute Review Board approved chart review of all adult patients transplanted between March 2008 and February 2018 was performed. This retrospective study was conducted on 323 LDLT and was performed at Ain Shams Organ Transplant Center (ASCOT) in Ain Shams Specialized Hospital.

\section{Contraindications to liver transplantation:}

- Severe psychiatric or neurologic disorder or absence of family/social support which is likely to impair compliance with medical care.

- Active/uncontrolled systemic infections.

- Irreversible significant myocardial dysfunction.

- Irreversible pulmonary diseases with marked hypoxemia.

- Presence of untreatable cancer or a history of cancer outside the liver without a likelihood of cure.

- Prior noncompliance with medical care which is likely to impair compliance with post-transplant medical care.

- Multiple medical co-morbidities that significantly increases the operative risk for liver transplantation.

- [7] pediatric patients were excluded from the study.

Hepatic artery reconstruction was performed by end to end anastomosis after reconstructing of both hepatic and portal veins followed by the reperfusion of the graft using Donor right HA to recipient right $\mathrm{HA}$ in case of right lobe graft and using donor left HA to recipient left HA in case of left lobe graft with interrupted non-absorbable monofilament 8-0 (polypropylene suture) using, 3.5 or $4.5 \mathrm{X}$ loupe magnification. Intraoperative Doppler ultrasound was performed to check arterial anastomosis. Antiplatelet agents were started intra operative and start post-operative when platelet $>50,000$.

All patients underwent Doppler ultrasonography every day during the first week post-operative, every 48 hours during the second post-operative week, twice per week till 1 month post-operative and then once per week till 3 months to confirm patency. Also, Doppler is performed urgently in case of marked elevation of the serum bilirubin and transaminase levels.

Patients who developed hepatic artery complications were identified. Hepatic artery complications like thrombosis, stenosis or pseudoaneurysm were diagnosed with Doppler ultrasound and confirmed by CT angiography; while bleeding from arterial anastomosis diagnosed during re-exploration due to postoperative bleeding.

Demographic data, MELD score, ICU stay, hospital stay, were recorded. Types of hepatic artery complications and management by surgical or radiological intervention and/or medical were reported.

\section{Results}

Three hundred and twenty-three patients have been transplanted between March 2008 till February 2018 (Table 1).

The etiology of liver disease and indication for transplantation was listed in (Table 2).

All recipients received right lobe graft except 5 patients received left lobe $(1.5 \%)$.

Hepatic artery anastomosis was performed using: 12 recipients left $\mathrm{HA}, 297$ right $\mathrm{HA}, 8$ splenic A and 6 LT gastric artery. Mean MELD was 22, ICU stay 6 days, hospital stay 28 days. Early hepatic artery thrombosis occurred in 6 patients $(1.8 \%)$ diagnosed with Doppler ultrasound and all were managed surgically; 5 patients were underwent thrombectomy and reanastomosis of the hepatic artery while one patient was explored and revision of arterial anastomosis was done using reversed splenic artery due to dissected hepatic artery intima. Unfortunately, HAT occurred again in 2 patients after 10 days, 21 days and the patients died.

Two patients were urgently retransplanted; one was successfully done within 48 hours using left gastric artery and the other was done after 34 days posttransplant but the patients were died 4 days postoperative. In the retransplant, we used a right lobe graft with a $10 \%$ steatosis and Graft Recipient 
Weight Ratio (GRWR) 0.84 with no variants in the hepatic veins, arteries, biliary and portal anatomy.

Late hepatic artery thrombosis occurred also in 4 patients $(1.2 \%)$ diagnosed with Doppler and confirmed with C-T angiography; 3 hepatic arteries recanalized with anticoagulant after 5, 7 and 8 months respectively. The 4 th patient developed recurrent cholangitis and intra hepatic biliary abscess at segment VIII which was successfully managed surgically by liver resection Fig. (1).

Hepatic artery stenosis occurred in 2 patients $(0.6 \%)$ after 35 days and 42 days. The patient successfully treated by interventional radiology dilatation with stent insertion. The other patient died 2 days later due to graft failure.

One patient developed bleeding from the site of anastomosis on day 1 post-operative needed reexploration and secured by 2 stitches.

Table (1): Demographic data.

\begin{tabular}{lc}
\hline Male/female & $280 / 43(87 \% / 13)$ \\
\hline Age & $19-65$ years \\
Weight & $53-120 \mathrm{~kg}$ \\
BMI & $22-35$ \\
\hline
\end{tabular}

BMI: Body Mass Index.
Table (2): Indications of living donor liver transplant.

\begin{tabular}{lc}
\hline Aetiology & Number \\
\hline HCV & 177 \\
HCV + HCC & 112 \\
HBV + HCC & 7 \\
HCV + HBV & 4 \\
HBV & 4 \\
AIH + HCV & 5 \\
Cryptogenic & 8 \\
BCS & 4 \\
Retransplant & 2 \\
\hline Total & 323 \\
\hline
\end{tabular}

\begin{tabular}{ll}
\hline $\mathrm{HCV}$ : Hepatitis C Virus. & AIH : Auto Immune Hepatitis. \\
HCC : Hepatocellular Carcinoma. & BCS : Budd Chiari Syndrome.
\end{tabular}
HCC : Hepatocellular Carcinoma. BCS : Budd Chiari Syndrome. HBV : Hepatitis B Virus.
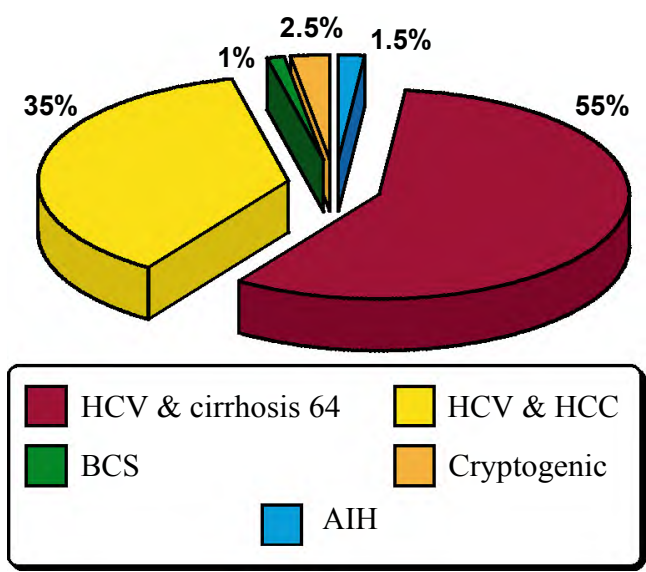

Fig. (1): Indication for liver transplantation.
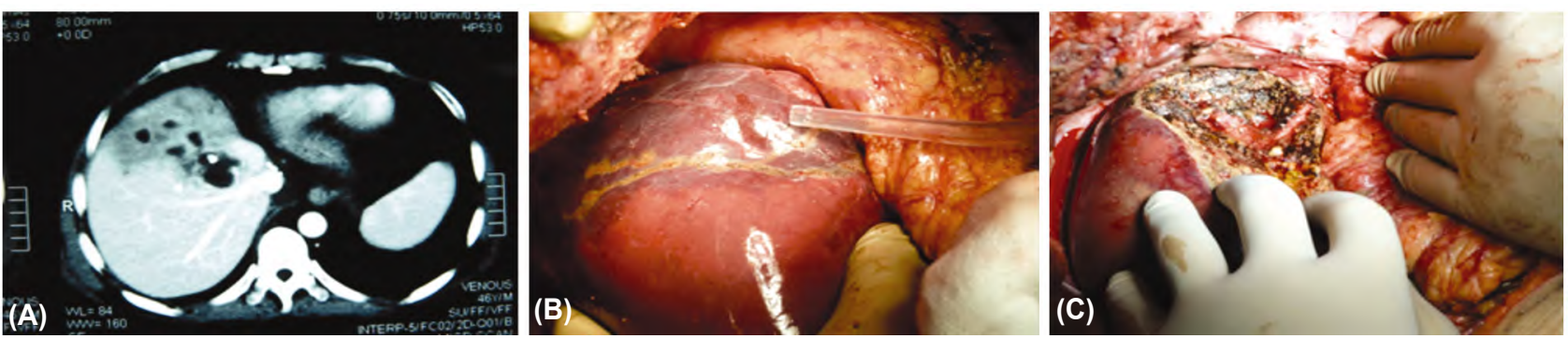

Fig. (2): (A) Abdominal CT showing intra-hepatic (graft) biliary abscess. (B) Intraoperative intrahepatic abscess before and (C) after resection segment VIII.

\section{Discussion}

Hepatic Artery Thrombosis (HAT) is the most common surgical complication after liver transplantation. A single definition of an early HAT is not universally accepted, with the time of presentation varying from 2 weeks to 3 months. However, for practical purposes, HAT within 1 month of LT is a clinically useful definition. Late HAT causes, occurring more than 3 months after Liver Transplant, are less well defined [6].

Complications associated with hepatic artery reconstructions are one of the major causes of graft loss and mortality after OLT. The early complications of hepatic artery were usually caused by technical problems. The late complications of hepatic artery were usually associated with a hypercoagulable state, over transfusion of platelets and fresh frozen plasma during the surgery, severe rejection and bile leakage [7]

Common causes of hepatic artery complications post liver transplant are the anatomical variations, diameter and length of hepatic artery, and injury to vessels including prolonged clamping of hepatic artery, kinking of a long artery, and hematoma of artery wall from improper flushing after clamping 
during operation, and the quality of recipient vessels and mismatch between donor and recipient arterial vessels and should be carefully considered and managed intraoperative [8].

The early HAT is usually silent and is often identified during a routine postoperative ultrasound examination before the development of complications [9].

A reliable source is the right gastroepiploic artery because it can be easily mobilized toward the hepatic hilum after detachment from the greater curvature of the stomach and can be promptly enlarged in case of a size mismatch after splenic artery ligation. The clinical significance of this artery has been proven in LD transplants [10-12] If it is not possible to use this artery in the retransplant, the interposition artery graft from the autogenous inferior mesenteric artery or sigmoidal artery can be used, or a fresh arterial deceased donor graft should be procured.

However, our cases are unique as we used the left gastric artery due to lack of cadaveric vascular conduits and mismatch between the size of recipient gastroepiploic and donor right hepatic arteries. This was also preferred as it entails a single anastomosis rather than an interposition arterial conduit with two anastomoses. Also, biliary anastomosis using duct to duct anastomosis was performed after viability of the bile duct was guaranteed.

Donor and recipient operations were scheduled so that cold preservation time of the liver graft and the LD operative time were minimized as previously reported by Totsuka and his colleagues [13] For this type of retransplant, the volume and quality of the second liver graft and the hepatic arterial inflow source should be considered prudently. This type of retransplant is often performed in a highly morbid situation, so the suboptimal donor graft (such as a graft smaller than $40 \%$ of the recipient's standard liver volume, an older LD liver, or a steatotic liver) should not be used [14,15].

In our case, we used a right lobe graft with a $10 \%$ steatosis and a GRWR 0.84 with no variants in the hepatic veins, arteries, biliary and portal anatomy. Donor livers with a variant anatomy, such as a variant portal vein or hepatic artery, should be cautiously used [16]. We thoroughly investigated recipients for a possible cause for early hepatic artery thrombosis after exclusion of technical and infectious causes, apart from elevated lupus anticoagulant, and factor V Leiden mutation thrombophilia workup revealed no abnormalities.
Schwetze [17] and Turner [18] previously reported the value of factor $\mathrm{V}$ Leiden mutation and activated protein $\mathrm{C}$ resistance in recurrent mesenteric thrombosis. This is the first living donor retransplant in Egypt, Africa, and the Middle East. To the best of our knowledge, this is the first living donor retransplant (LD after LD) using the left gastric artery for arterial reconstruction in the retransplant for hepatic artery thrombosis. Also, the use of left gastric artery for arterial reconstruction and radiological intervention early after LDLT were not commonly previously reported.

Antiplatelet prophylaxis can effectively reduce the incidence of late HAT after liver transplantation. Vivarelli et al., reported an overall incidence of late HAT of $1.67 \%$ with a median time of presentation of 500 days; late HAT was reported in $0.4 \%$ of patients who were maintained on antiplatelet prophylaxis compared to $2.2 \%$ in those who did not receive prophylaxis [19].

The hepatic artery supplies the bile ducts of the graft; HAT can lead to biliary ischemia, necrosis, stricture, sepsis, and ultimately hepatic insufficiency and graft loss.in the present study one patient complaint of recurrent attack of biliary cholangitis and liver necrosis inspite of development collateral with anticoagulant treatment this is agrees with Fouzas and colleague study [20] who proved this group of patients treated conservatively and developed hepatic arterial collaterals is a high risk for biliary complications and sepsis.

Relatively, HAS can be treated more easily. Percutaneous transluminal angioplasty and intraluminal stents are safe procedures for HAS occurring several weeks after liver transplantation. If performed within the early post-operative period, angioplasty may rupture the suture line or dissect the intima [21]. In this study, the patient with HAS was successfully treated with balloon angioplasty and endoluminal stent placement at the same time.

\section{Conclusion:}

Proper treatment of hepatic artery complications is required to achieve better survival among patients undergoing LDLT. Conservative management should be used in selected cases. Arterial reconstruction using left gastric artery is feasible. Emergency Liver retransplantation is lifesaving in cases of HAT. Early diagnosis and surgical management for early HAT and radiological intervention or medical treatment for late HAT are the cornerstone to save the recipient. 


\section{References}

1- TANAKA K.: Progress and future in living donor liver transplantation, Keio J. Med., 52 (2): 73-9, 2003.

2- KIM B.S., TAE K.K. and JUNG D.J.: Vascular Complications After Living Related Liver Transplantation: Evaluation with Gadolinium-Enhanced Three-Dimensional MR Angiography, 181: 467-74, 2003.

3- PAWLAK J., BLEWSKI T.W., MALKOWSKI P., NYCKOWSKI P., ZIENIEWICZ K., GRZELAK I., ALSHARABI A., MICHALOWICZ B., KRAWCZYK M. and KARWOWSKI A.: Vascular Complications Related to Liver Transplantation, transplantation proceedings, 32: $1426-8,2000$

4- BEKKER J., PLOEM S., De JONG K.P.: Early hepatic artery thrombosis after liver transplantation: A systematic review of the incidence, outcome and risk factors. Am. J. Transplant., 9: 746-57, 2009.

5- YOUNG E.K., KYOUNG T.K., NYUN P.K. and YOUNG A.K.: Hepatic Vein Stenosis after Living Donor Liver Transplantation: Evaluation with Doppler US, Radiology, 229: 806-10, 2003.

6- HERRERO J.I., LUCENA J.F., QUIROGA J., SANGRO B., PARDO F., ROTELLAR F., et al.: Liver transplant recipients older than 60 years have lower survival and higher incidence of malignancy. Am. J. Transplant., 3: 1407-12, 2003.

7- ZHAO J.C., SHI-CHUN L. and LU-NAN Y.: Incidence and treatment of hepatic artery complications after orthotopic liver transplantation, World J. Gastroenterol., 9 (12): 2853-5, 2003.

8- ZHAO J.C., HUANG F.G., LU S.C., YAN L.N., LI B., JIN L.R., WEN T.F., WANG J., LUO Y. and PENG Y.L.: Reconstructions of hepatic artery in orthotopic liver transplantation. Zhonghua Qiguan Yizhi Zazhi, 23: 379, 2002.

9- HOLT A.P., THORBURN D., MIRZA D., GUNSON B., WONG T. and HAYDON G.: A prospective study of standardized nonsurgical therapy in the management of biliary anastomotic strictures complicating liver transplantation. Transplantation, 84: 857-63, 2007.

10- SINGHAL A., STOKES K., SEBASTIAN A., et al : Endovascular treatment of hepatic artery thrombosis following liver transplantation. Transplantation Int., 23: $245,2010$.
11- WEI W.I., LAM L.K., NG R.W., et al.: Microvascular reconstruction of the hepatic artery in live donor liver transplantation: Experience across a decade. Arch. Surg., 139: 304, 2004.

12- YAO F.Y., SAAB S., BASS N.M., et al.: Prediction of survival after liver retransplantation for late graft failure based on pre-operative prognostic scores. Hepatology, 39: 230, 2004.

13- TOTSUKA E., FUNG J.J., LEE M.C., et al.: Influence of cold ischemia time and graft transport distance on postoperative outcome in human liver transplantation. Surg. Today, 32: 792, 2002.

14- KIUCHI T., TANAKA K., ITO T., et al.: Small-for-size graft in living donor liver transplantation: How far should we go? Liver Transpl., 9: S29, 2003.

15- ITO T., KIUCHI T., YAMAMOTO H., et al.: Changes in portal venous pressure in the early phase after living donor liver transplantation: Pathogenesis and clinical implications. Transplantation, 75: 1313, 2003.

16- MARCOS A., ORLOFF M., MIELES L., et al.: Reconstruction of double hepatic arterial and portal venous branches for right-lobe living donor liver transplantation. Liver Transpl., 7: 673, 2001.

17- SCHWETZE S.M. and LINENBERGER M.: Acquired protein $\mathrm{S}$ deficiency with multiple thrombotic complications after orthotopic liver transplantation. Transplantation, 67: 1366-9, 1999.

18- TURNER S.M. and PROBERT C.S.J.: Factor V Leiden presenting as recurrent mesenteric artery thrombosis. CME J. Gastroenterol. Hepatol. Nutr., 2: 17-20, 1992.

19- VIVARELLI M., CUCCHETTI A., La BARBA G., BELLUSCI R, De VIVO A., NARDO B., CAVALLARI A. and PINNA A.D.: Ischemic arterial complications after liver transplantation in the adult: Multivariate analysis of risk factors, Arch. Surg., 139: 1069-74, 2004.

20- FOUZAS I., SKLAVOS A., BISMPA K., PAXIADAKIS I., et al.: Hepatic Artery Thrombosis After Orthotopic Liver Transplantation: 3 Patients With Collateral Formation and Conservative Treatment. Transplantation Proceedings, 44: 2741-4, 2012.

21- JIANG L., YANG J., CHEN W., et al.: Vascular and biliary complications after liver transplantation: Interventional Treatment. Chin. Med. J., 115: 1679, 2002. 


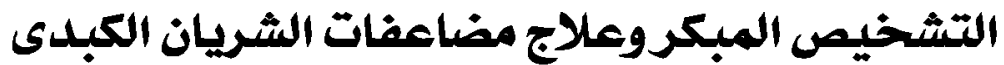

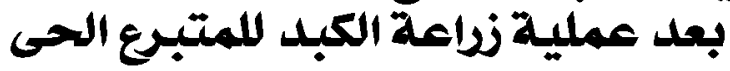

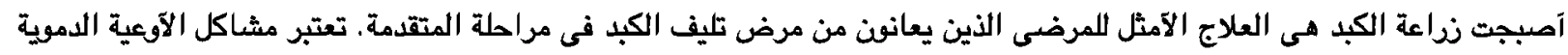

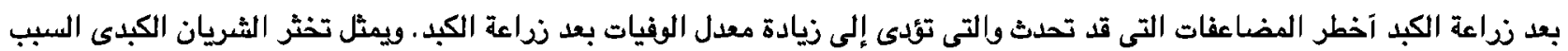
الرئيسى لزيادة معدل الوفيات بعد زراعة الكبد.

الهدف من هذه الدراسة هو تقييم مضاعفات الشراين الكبدى بعد زراعة الكبد المتبرعين الآحياءوالتشخيص المبكر والطرق المختلة لعلاج هذه المضاعفات.

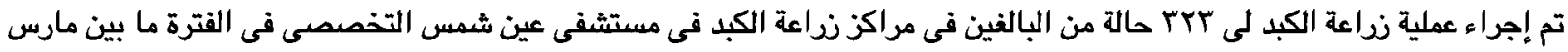

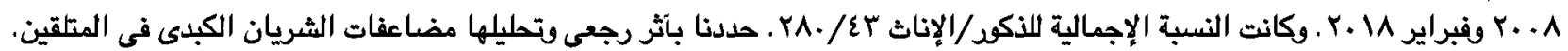

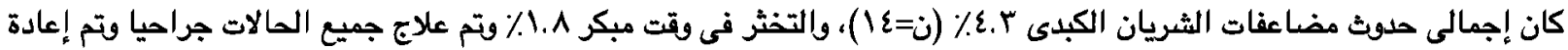

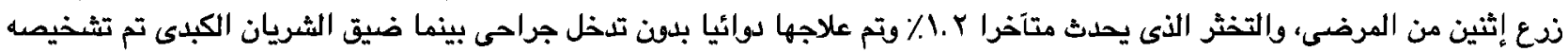

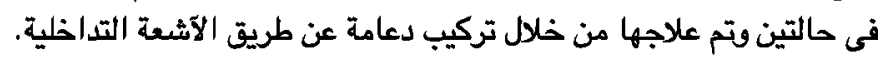

مطلوب الوقاية والعلاج المناسب لمضاعفات الشريان الكبدى لتحقيق نتائج آفضل بين المرضى الذين يخضعون لإجراء عملية زراعة الكبد. 